\title{
Evaluation of Aflatoxins and Pesticide Residues in Fresh and Different Processed Mushrooms
}

\author{
Abu Saleh Mostafa Kamala*, Abul Khair a, Mamtaz Dawlatanab, M Tariqul Hassan', \\ Fauzia Begumb ${ }^{b}$ and Matiur Rahim ${ }^{b}$ \\ ${ }^{a}$ Dept. of Botany, Jahangirnagar University, Savar, Dhaka. ${ }^{b} I F S T: B C S I R$; \\ Dr.Qudrat-I-Khuda road, Dhaka-1205.Bangladesh.
}

\begin{abstract}
Mushrooms are becoming popular to us due to their nutritional, medicinal and therapeutic values. Toxicity of aflatoxins, presence of DDT and heptachlor as pesticide residue are rare in edible mushrooms but not non-existent. So an attempt has been made to determine its presence and to the same quantify using HPLC and GC. Total seven categories of mushrooms and mushroom-based food products were ana-

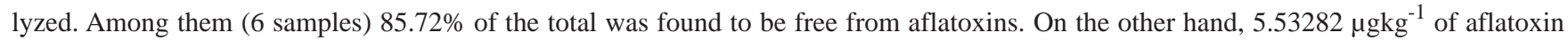
$\mathrm{B}_{1}$ was found to be present in canned Button mushrooms (Agaricus spp).The results revealed that $14.28 \%$ (1 sample) of samples were toxicated by aflatoxin $\mathrm{B}_{1}$, compare to the total samples analyzed including the imported was in the form of processed/preserved mushrooms. In the present experiments it was also observed that there were no aflatoxins in fresh-cut mushrooms and in the recently developed Mushroom-juice even in dried and powdered as processed Oyster mushrooms (Pleurotus ostreatus) which are being widely cultivated in Bangladesh. No pesticide residue such as DDT or heptachlor was detected in any of the samples examined.
\end{abstract}

Key words: Mushrooms, Oyster, Button, Aflatoxins, DDT, Heptachlor; Pesticide residue.

\section{Introduction}

Aflatoxins are a group of highly toxic secondary metabolites known to be produced by Aspergillus flavus and Aspergillus pasiticus (Codner 1963; Sargeant et al, 1971). These are ubiquitous in nature, associated with the spoilage and toxin production of stored, agricultural commodities (Diener,1977). Considerable importance is associated with the presence of aflatoxins in food and feed because of their carcinogenic, mutagenic and teratogenic effects (Golblatt, 1969; Healthcate, 1978). Approximately 300 to 400 substances are recognized as mycotoxins, comprising a broad variety of chemical structures (Sulyok et al, 2006). It has also been known that mycotoxins are toxic secondary metabolites produced by various mold species growing on many agricultural commodities and processed food, either in the field or during storage (Hussein and Brasel, 2001; Bennett and Klich, 2003). Mycotoxins have been ranked as the most important chronic dietary risk factor, higher than synthet ic contaminants, plant toxins, food additives or pesticide residue (Kuiper, 1998). Lately, additive and synergistic have been observed concerning the health hazard posed by mycotoxins (Mello et al.1999; Speijers, 2004; McKean et al, 2006). The nutritional and medicinal values of mushrooms have long been recognized (Lucas et al,1957; Suzuki and Oshima 1976). On accounts of their flashy nature and good flavor, it is being used various types of snacks and ready to eat products (Bruhn, 1995). By 2003, world mushroom production had reached three million tones and a trend to increase by $10 \%$ every year (Anon, 2003; Thaithatgoon, 1998). During the past few decades, it has been increased the demand of easier-to-prepare fresh vegetables to a healthy diet. However, mushrooms have assumed greater importance in the diets of both rural and urban dwellers. Most recently, these fresh mushrooms and mushroom-based food items are consumed by consumers of varied age groups (Valentine, 1995). Recently mushrooms are becoming popular in Bangladesh. An on average 3 tons of mushrooms are being imported per year (Anon, 2006). While 620-675 metric tons of mushrooms are produced in Bangladesh per annum, majority of $97 \%$ are Oyster mushrooms (Pleurotus spp). In Bangladesh, mushrooms are being cultivated mainly in polypropylene (pp) bags preparing spawn and few in making compost. The two main substrate or the basal components of

\footnotetext{
*Corresponding Author, Email:kamal_asm@yahoo.com
} 
the spawn are sawdust and paddy straw, other supplementary agro-wastes are rice husk and wheat bran (Kamal, 2008). It has been Reported that about 30 million tones of agricultural wastes like saw dust, paddy straw, wheat straw and sugarcane- bagasse are produced per annum in Bangladesh (Ahmed, 2001). As mushrooms can build up large concentrate of some of the toxins, there is possibility of present of heptachlor and DDT as pesticide residues in these agrowastes. It has been pointed out by Mello (1997) that food processors must also recognize increased costs related to further processing requirements, in particular, analysis and monitoring for presence of the afflatoxins. However, little is known about aflatoxins and pesticide residues in mushrooms. So, an attempt has been taken with a view to evaluate aflatoxins, and pesticide residue in both of fresh and processed edible mushrooms.

\section{Materials and Methods}

\section{Collection of samples:}

Fresh-cut Oyster mushrooms (Pleurotus ostreatus) are collected as of third flash from the Cropping room of IFST, BCSIR, Dhaka. The substrates were sawdust $\left(\mathrm{FM}_{1}\right)$ and paddy straw $\left(\mathrm{FM}_{2}\right)$ respectively. The sizes of mushrooms are in between 5 to $11 \mathrm{~cm}$ in diameter on an average $8 \mathrm{~cm}$, and did not require use of pesticide in both of pre-harvest or postharvest stages. Oven dried mushroom powder (MP1), mushroom soup powder (MP2) and recently developed Mushroom-Juice (MJ) are collected from the same laboratory as processed mushrooms. The canned (M;GM) White button mushrooms (Agaricus spp) were imported and collected randomized from mega shops of Dhaka city considered to be processed /preserved foods. Total seven categories of samples are collected and three replicates of each sample are analyzed.

\section{Instruments/Apparatus}

Detection and quantification of Aflatoxins, Ochratoxcins were performed with a High Performance Liquid Chromatograph (HPLC), Agilent1200, G1316A, CULCOM, German. Heptachlor and DDT were analyzed using GasChromatography (GC-14B Shimadzu) with an electron capture detector (ECD), a manual sampler and solution software. Syringe (10 $\mu$; Hamilton co.). Concerned instruments/apparatus are rinsed with acetone prior to use.

\section{Reagents}

Acetone, diethyl ether, dimethyl formamide saturated with petroleum ether, n-hexane, petroleum ether $\left(30-60^{\circ} \mathrm{C}\right)$, petroleum ether $\left(30-60^{\circ} \mathrm{C}\right)$ saturated with dimethyl for- mamide, eluting mixture I (petroleum ether+diethyl ether 94:6v/v), standard solutions, eosin solution (2 mg in $100 \mathrm{ml}$ ), sodium sulfate solution (2g/100ml $\left.\mathrm{NaSo}_{4} 10 \mathrm{H}_{2} \mathrm{O}\right)$, sodium sulfate anhydrous (heated for at least 2 hour at $550^{\circ} \mathrm{C}$ ), florisil 60-100 mesh (heated for at least 2 hour at $550^{\circ} \mathrm{C}$, cool and stored in tightly stopper- container, prior to use was heated for at least 5 hour at $130^{\circ} \mathrm{C}$, cool and add $5 \% \mathrm{w} / \mathrm{w}$ water, the mixture was shaken for at least $20 \mathrm{~min}$ and was stored in a container for at least 10 hour), cotton wool.

Chemicals, reagents and solvents used for the analysis were procured form MERCK, Germany. DDT and heptachlor standards were obtained from Sigma Chemicals.

\section{Sample preparation:}

All the samples were blended while comminuting was avoided by brief chopping for several times. Titration was done with $25 \mathrm{~g}$ of sample and sodium sulfate to get dry powdery mixture, with the aid of an extraction thimble; the powdary mixture exhaustively with Petroleum Ether in Soxhlet apparatus. Concentrate and dilute to $25 \mathrm{ml}$ with petroleum ether saturated with dimethyl formamide (Hans and Zeumer, 1987).

\section{Clean up}

Preparation of injecting solution and clean up was performed according to the method described by Hans and Zeumer (1987).

Procedure for aflatoxins: To get injecting solution, the required amount of fresh-cut mushrooms or mushroombased food products were weighted and then blended with the help of high-speed blender fitted with proof glass jar and explosion-proof mater to make slurry. Added acetone and distilled water to make it soluble using the formulae.

Vol. of acetone to be added

$$
=\frac{\text { Slurry wt x D. water: Meal x } 4}{\text { D. water: Meal }+1}
$$

Shacked 30 minutes using shaker (rm 521, DENLEY. UK) and filtered by whatman filter paper (Whatman- ${ }^{1}$ cat no 1001320; UK). Subsequently the solid phase extraction (SPE) was done by Vacuum manifold (Model No. 12234000) using Varian Bond Eluted column (PH 1210-2032) Followed wash columns for absorbing color and elution two additional columns for absorbing color and moisture (florisil magnesium tricillicate for cc and sodium sulphate for moisture) then eluted with elution buffer (Chloroform). Concentrated the extract with the help of concentrator (Techne, DB-3, UK) under nitrogen gas. Finally extracting were diluted with $300 \mu \mathrm{l}(.3 \mathrm{ml})$ mobile phase (Methanol 
$22.5 \%$ + Acetonitrile $22.5 \%+55 \%$ Deionized water) as injecting solution. In order to get results as computerized chromatogram, $30 \mu$ l solution was injected into the HPLC with the help of $10 \mu$ l syringe and run for 15 minutes.

\section{Procedure for DDT and heptachlor}

The DDT and heptachlor residues were analyzed by GC148, Shimadzu with an electron capture detector (ECD), a manual sampler and GC solution software. A column of $3.1 \mathrm{~m}$ X $3.2 \mathrm{~mm}$; I. D glass spiral; stationary phase silicon OV $17,5 \%$, aging $300^{\circ} \mathrm{C}$, support chromosorb-W-AWDMCS, mesh $80 / 100,1 \mu m$ film thickness was used for the chromatographic separation of insecticides.

The temperature was fixed for the injector at $250^{\circ} \mathrm{C}$, column at $280^{\circ} \mathrm{C}$, detector at $280^{\circ} \mathrm{C}$. The carrier gas was nitrogen with a $60 \mathrm{ml} / \mathrm{min}$-flow rate. $1.0 \mu \mathrm{l}$ sample was injected for each run and the running time was $25 \mathrm{~min}$. Standards peak were identified by injecting high concentration of the standard (0.5 ppm and 0.25ppm) and the retention time for DDT and heptachlor were determined. Then calibration was done at 3 points (25 ppb, $50 \mathrm{ppb}$ and 100ppb) by composite stock standard solution. GC system was calibrated using external standard technique. Individual standard stock solution (100mg/l) was prepared by weighing appropriate amounts of Teflon-lined screw cap and dissolving the weighed standard in HPLC grade hexane. Stock standard solution was used to prepare primary dilution standards. Appropriate volume of each individual stock solution was taken in a volumetric flask and mixed the solutions to obtain composite stock standard solution.

\section{Detection and quantification}

Gas chromatograph equipped with ECD was checked for linearity. Instrumental limit of detection for GC-ECD was
$1.0 \mu \mathrm{g} / \mathrm{l}$ for organochlorine pesticides. An aliquot of mushroom samples which were collected as blank and treated exactly as a sample including exposure to all glassware, equipments, solvents and regents was used with the sample matrix. No analytic peak was detected in laboratory reagent blank. Aliquot of fortified samples matrix were prepared to which known quantities of the pesticides were added in the laboratory in ppb range. This laboratory fortified matrix was analyzed exactly like the sample. Extraction and clean up were done as mentioned and the recoveries formed untreated control samples of mushrooms, fortified with the analyzed compounds at level of 25ppb were 96-100\% for heptachlor and 98-100\% for DDT.

Prior to injection of the first sample solution, a standard solution was injected at least three times to check the operating conditions and the constancy of the detector signals. Further linearity of the ECD signal was checked by injecting serial dilutions of DDT and heptachlor. A standard solution injected after at least every other sample solution due to column contamination so that any alterations of the gas chromatographic system could be recognized.

\section{Results and Discussion}

Results obtained from the experiments are summarized in Table I. Fig.-1 showed that there was no peak for afflatoxins in any sample (FM-1, FM-2, M, GM, MJ, and MP$1 \& \mathrm{MP}-2)$ considering retention time as specified for mentioned HPLC. It indicated that there was not found any aflatoxins in fresh or processed Oyster mushrooms or might be present below the detection limit (.01ppb), generally recognized as insignificant. Bano et al. (1986) have been studied 12 mycotoxins including aflatoxins $B_{1} ; B_{2}$ in the spent straw after development of Pleurotus sajor-casu fruting bodies. When fed to albino rats and mice of both sex no biological or histopathological abnormalities were found. No toxic

Table I. Tabular form of the results of Aflatoxin and Pesticide residue in frest and different Processed and preserved mushrooms.

\begin{tabular}{c|c|c|c|c|c|c|c|c|c|c}
\hline $\begin{array}{c}\text { Sl. } \\
\text { No. }\end{array}$ & Code & Sample & Packet & Origin & Substrate & \multicolumn{4}{|c|}{ Aflatoxin } & Pesticide \\
\cline { 5 - 8 } & & & & & & $\mathrm{B}_{1}$ & $\mathrm{~B}_{2}$ & $\mathrm{G}_{1}$ & $\mathrm{G}_{2}$ & residue \\
\hline 1 & FM-1 & Fresh oyster & 100g polypack & Local & Sawdust & $\mathrm{A}$ & $\mathrm{A}$ & $\mathrm{A}$ & $\mathrm{A}$ & $\mathrm{ND}$ \\
2 & FM-2 & Fresh oyster & 100g polypack & Local & Straw & $\mathrm{A}$ & $\mathrm{A}$ & $\mathrm{A}$ & $\mathrm{A}$ & $\mathrm{A}$ \\
3 & $\mathrm{GM}$ & Button & $450 \mathrm{~g}$ cane & Imported & Unknown & $\mathrm{A}$ & $\mathrm{A}$ & $\mathrm{A}$ & $\mathrm{A}$ & $\mathrm{A}$ \\
4 & $\mathrm{M}$ & Button & $450 \mathrm{~g}$ cane & Imported & Unknown & $\mathrm{P}$ & $\mathrm{A}$ & $\mathrm{A}$ & $\mathrm{A}$ & $\mathrm{ND}$ \\
5 & MJ & Juice (oyster) & $250 \mathrm{ml}$ bottle & Local & Straw & $\mathrm{A}$ & $\mathrm{A}$ & $\mathrm{A}$ & $\mathrm{A}$ & $\mathrm{ND}$ \\
6 & MP-1 & Powder (oyster) & 100g polypack & Local & Straw & $\mathrm{A}$ & $\mathrm{A}$ & $\mathrm{A}$ & $\mathrm{A}$ & $\mathrm{ND}$ \\
7 & MP-2 & Soup powder & 100gm polypack & Local & Sawdust & $\mathrm{A}$ & $\mathrm{A}$ & $\mathrm{A}$ & $\mathrm{A}$ & $\mathrm{ND}$ \\
\hline
\end{tabular}

Key: $\quad A=$ Absent; $\mathrm{P}=$ Present; ND= Not done (As because, in case of sl. No-1, substrate was not susceptible and sl. No 47 samples were derived from Fresh Oyster mushrooms). 


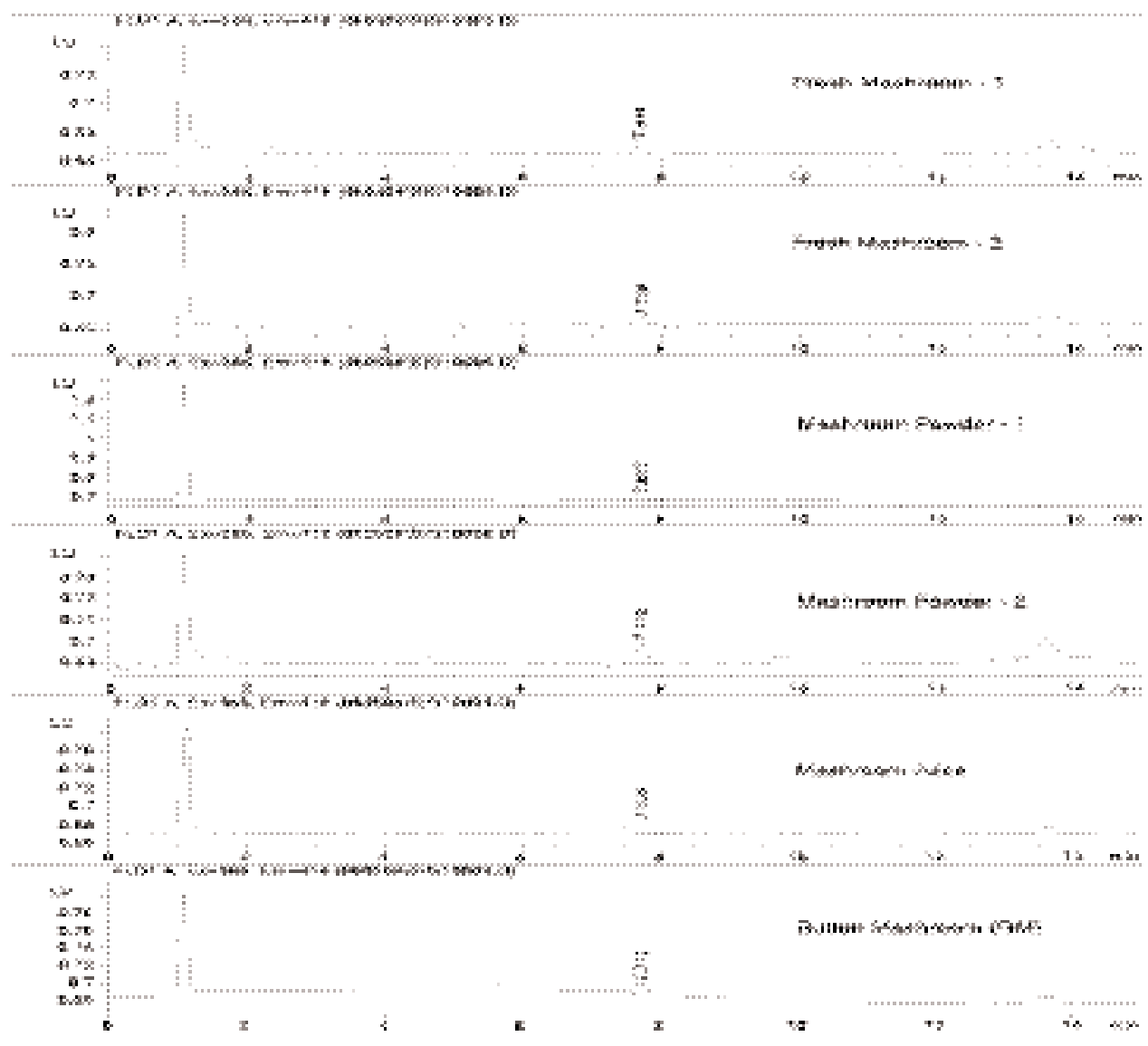

effects or illness sign occurred in chick or pigs. A number of literatures revealed that mushrooms have the ability to accumulate toxic substances from substrate through mycelium. In such finding we can assumed that the observation was similar with that of Bano et al. findings in case of Oyster mushrooms (Pleurotus spp) and these types of mushroom-based food products. As can be seen in Fig. 2, aflatoxin- $B_{1}$ has found to be present in White button mushroom. The amount was $5.53282 \mu$ gkg- $_{-1}$. Mori et al, (1978) have already been reported about aflatoxin-b toxicity as mycotoxin which is closely related to hepatocarcinogenicity from Aspergillus flavus in several mushrooms and Agaricus bisporus is included in this group. It was evident that toxins in edi-ble mushrooms are rare but not non-existent specially in White button mushrooms. Considering the carcinogenic effects of afflatoxins on animal and human, there are statuary limits or in some cases advisory guidelines for the maximum levels of the afflatoxins permitted in foods and feeds through out the world (Friesen and Garren 1982). The Food and Drug Administration (FDA) has established more specific guideline on acceptable levels of afflatoxins in human foods and animal feeds.
Within the EC, individual member states have already adopted regulations and recommendations respecting maximum permitted levels of afflatoxins $\mathrm{B}_{1}$ and $\mathrm{M}_{1}$. The intake limits for humans of about $0.15 \mathrm{ng} / \mathrm{kg} /$ day for afflatoxins $B_{1}$ and $0.20 \mathrm{ng} / \mathrm{kg} /$ day for afflatoxins $\mathrm{M}_{1}$ (CSHPE,1999).There are no such type of limiting value specified by Bangladesh. Usually, Bangladesh follows the recommendation of FDA. Our observed value was much higher than that of specified limits. It would be much helpful for us to consumption of imported White button mushroom but it should keep in mind that the results do not represents the whole samples. It may occurre in the particular collected sample or laid with in the specified lot.

Now, It is clear that when afflatoxin contamination does occur at levels above the legal limit it can lead to significant loss and may also be detrimental for health and health policy. From the processing and preservation point of view, we do agree with the opinion passed by Charmley that the extent of afflatoxins presence and concomitant economic loss is now becoming more generally recognized (Charmley et al, 1995). In the course of these experiments, it was observed 


\begin{tabular}{lcccc}
$\begin{array}{c}\text { RetTime Type } \\
\text { [min] }\end{array}$ & $\begin{array}{c}\text { Area } \\
\text { LU }\end{array}$ & Ant/Area & $\begin{array}{c}\text { Anount } \\
\text { [ppb] }\end{array}$ & Grp Name \\
\hline 6.052 & - & - & - & Aftx G2 \\
6.958 & - & - & - & Aftx G1 \\
8.474 & - & - & - & Aftx B2 \\
9.929 BPA & $1.61403 \mathrm{e}-1$ & 34.27958 & 5.53282 & Aftx B1 \\
Totals : & & & & \\
\end{tabular}

that between 7.701 to 7.953 retention times there was a peak in both of Oyster and Button mushrooms. It seemed that the indicated peak may be a characteristic of fungi.

As per Fig. 3 and Fig. 4, it was clear that there was no DDT and Heptachlor as pesticide residue are not to be found in any sample examined. Absent of DDT and Heptachlor also indicated that the components of the substrates were free from pesticide residues.

\section{Conclusion}

Afflatoxins and pesticide residues have been viewed as an unavoidable contaminants in course of practices. Hence, more attention as to purity of import commodities like mushrooms processed or preserved are to be paid and at the same time, care should be taken for using of the wastes needed as substrate for cultivating edible mushrooms. It is also to be noted that if there present such type of toxins in fresh or processed foods, then must be considered it's recommended daily intake (RDI).

\section{References}

Ahmed S. (2001) Development of mushroom varieties suitable for rural level in Bangladesh. Report presented in BARC Annual Review Programme. pp.3-4.

Anon (1999) Conseil Superieur d'Hygiene Publique de France(CSHPF) Les mycotoxines dans l'alimentation: evaluation et gestion du risqué,eds TEC \& DOC. 
Anon (2006) National Board of Revenue (NBR); Ministry of Internal Resource Division. Government of the People's Republic of Bangladesh. Official Data, Dhaka,

Anon (2003) FAO production year book. http:// faostat.fao.org.

Bennett J. W., and Klich M., Clin. Microbiol. Rev.2003; 16:497.DOI:10.1128/CMR.16.3.497-516.

Bruhn C. (1995) Consumer perception of fresh- cut produce Perishable Handling Newsletter, UC Davis1 (Feb): 18-19.

Charmley L. L., Trenholm H. L., Prelusky D. B., and Rosenberg A. (1995) Economic losses and decontamination, Nat.Toxins, 3: 199.

Ciegler A. R. E., Peterson A. A., and Logoda H. H. Hall. (1966) Aflatoxin production and degradation by $A$. Flavus in 20 L fermenter. 14(5): 826-833

Codner R. C., Sargeant K., and Yeo A. (1963) Production of affatoxin by the culture of strains of A. flavus oryzae on sterilized peanuts. Biotechnol Bioeng 5: 185-192.

Diener U. L., and Daris N. D. (1977) Aflatoxin formation in peanuts by Aspergilius flavus. Agricultural Experimental Station, Auburn University, Auburn, Ala. Bulletion 493.

Friesen M. D., and Garren L. (1982) International mycotoxins check sample programme.Part-ll, Report on Laboratory performance for determination of afflatoxinM1 in milk. J. Assoc. Off. Anal. Chem. 65: 864.

Golblatt L. A. (1969) Edited aflatoxin, Academic 9nc Press. New York.

Hans-Peter and Zeumer H. (1987) Manual of Pesticides Residue Analysis,vol,1, working group "analysis". Pesticide commission, Germany,VCH, pp 298-319.

Healthcate J. G., and Hibbert J. R. (1978) In: Aflatoxin,Chemical and Biological Aspects. Elsevier, New York.

Hussein H. S., and Brasel J. M. Toxicology 2001; 167:101 (vide Sulyok et al., 2006).

Kamal Abu Saleh Mostafa (2008). Paper presented in the seminar on Assessment of Biological Qualities of the Edible Mushroom in relation to Processing and Preservation to Develop Quality Food products. Dept. of Botany; Jahangir Nagar University (JU); Saver; Dhaka; Bangladesh.
Kuiper-Goodman T. (1998) In Mycotoxins and PhytotoxinsDevelopments in Chemistry, Toxicology and Food Safty,Miraglia M, van Edmond H, Brera C, Gilbert J (eds).Alaken Inc.: Fort Collins, CO,125.

Lucas E. H., Rigler R. L., Byrrum R. U., and Stock O. O. (1957) Tumor inhitiors in Boletus edulis and other holobasidiomycetes. Antibiot Chemother, 7: 1-4.

Suzuki S., and Oshima S. (1976). Influence of shiiteke (Lentinula edodes) on human serum cholesterol. Mushroom Sci, a (1): 463-7.

McKean C., Tamg L., Billam M., Tang M., Theodorakis C.W., Kendall R. J., and Wang J. S. (2006) J. Appl. Toxicol. 26:139. DOL: 10.1002/jat.1117.

Mello D., (1999) JPF,Placinta CM, MacDonald AMC. Anim. Feed Sci. Technol.1999; 40:183.

Mori K., Kuida K., Hosokawa D., and Takihara M. (1978). Virus-like particles in several mushrooms, Mushroom Sci., 10 (Part-I), 773-787.

Sargeant K. A., Sheridan J., and O'kelly R. B. A. (1971) Carnaghan. Cited in Microbial Toxins Edited by Detroy, R. W, Lillehoj, E.B and Ceiglar A. Academic Press, New York. Vol. 6.

Shotwell O. L., Smith M. L., and Hesseltine. C. W. (1973) Mycotoxin production by insecticide treatment of wheat. Cereal Chemistry, 50(3): 264-270.

Speijers G. J. A., and Spreijers M. H. M. (2004) Toxicol. Lett. 153: 91

Sulyok M., Berthiller F., Kraska R., and Shhuhmacher R. (2006) Development and validation of a liquid chromatography/ tandem mass spectrometric method for the determination of 39 mycotoxins in wheat and maize. Rapid Commun Mass Spectrom, 20: pp 2649-2659.

Suzuki S., and Oshima S. (1976) Influence of shiiteke (Lentinula edodes) on human serum cholesterol. Mushroom Sci, a (1): 463-T.

Thaithatgoon (1998) P, FAO. Training of Trainer. TPC/ THA/8821.Mushroom Training for Disabled people Bangkok, Thailand.)

Valentine A., and Aletor (1995) Compositional studies on edible tropical species of mushrooms. Food Chemistry; 54: 265-268.

Received : November, 10, 2008;

Accepted : December, 04, 2008 